SANDIA REPORT

SAND97-1156 • UC-704

Unlimited Release

RECFIVED

DEC 15 1997

Printed December 1997

\title{
Synthetic Molecular Receptors for Phosphates and Phosphonates in Sol-Gel Materials
}

Darryl Y. Sasaki, Todd M. Alam, Roger A. Assink, Charles E. Daitch, Carol S. Ashley, C. Jeffrey Brinker, Joseph S. Schoeniger, Diana C. Roe, Phillip I. Pohl, Daniel J. Rush, Kenneth J. Shea

Prepared by

Sandia National Laboratories

Albuquerque, New Mexico 87185 and Livermore, California 94550

Sandia is a multiprogram laboratory operated by Sandia corporation, a Lockheed Martin Company, for the United States Department of

Energy under Contract DE-AC04-94AL 85000.

Approved for public release; further dissemination unlimited. 
Issued by Sandia National Laboratories, operated for the United States Department of Eriergy by Sandia Corporation.

NOTICE: This report was prepared as an account of work sponsored by an agency of the United States Government. Neither the United States Government nor any agency thereof, nor any of their employees, nor any of their contractors, subiontractors, or their employees, makes any warranty, express or implied, or assumes any legal liability or responsibility for the accuracy, compleieness, or usefulness of any information, apparatus, product, or process disclosed, or represents that its use would not infringe privately owned rights. Reference herein to any specific commercial product, process, or service by trade name, trademark, manufacturer, or otherwise, does not necessa:ily constitute or imply its endorsement, recommendation, or favoring by thi United States Government, any agency thereof, or any of their contractors or subcontractors. The views and opinions expressed herein do not necessarily state or reflect those of the United States Government, any agency thereof, or any of their contractors.

Printed in the United States of America. This report has been reproduced directly from the best available copy.

Available to DOE and DOE contractors from

Office of Scien ific and Technical Information

P.O. Box 62

Oak Ridge, TN 37831

Prices available from (615) 576-8401, FTS 626-8401

Available to the pablic from

National Technical Information Service

U.S. Department of Commerce

5285 Port Royal Rd

Springfield, VA 22161

NTIS price codes

Printed copy: A03

Microfiche copy: A01 


\section{DISCLAMIER}

Portions of this docoment migy be illegible in electronic image produets. Imoges are produced from the best available original document 


\title{
Synthetic Molecular Receptors for Phosphates and Phosphonates in Sol-Gel Materials
}

\author{
Darryl Y. Sasaki, Todd M. Alam, Roger A. Assink, and Charles E. Daitch \\ Materials Aging \& Reliability Bulk Properties Department \\ Carol S. Ashley and C. Jeffrey Brinker \\ Direct Fabrication Technologies Department \\ Joseph S. Schoeniger and Diana C. Roe \\ Exploratory Systems Technologies \\ Phillip I. Pohl \\ Environmental Risk \& Regulatory Analysis \\ Sandia National Laboratories \\ P.O. Box 5800 \\ Albuquerque, New Mexico, 87185-1407
Daniel J. Rush and Kenneth J. Shea
University of California, Irvine
Department of Chemistry
Irvine, California 92717

\begin{abstract}
Synthetic receptors for phosphates and phosphonates have been generated in $\mathrm{SiO}_{2}$ xerogels via a surface molecular imprinting method. The monomer 3-trimethoxy silylpropyl-1-guanidinium chloride (1) was developed to prepare receptor sites capable of binding with substrates through a combination of ionic and hydrogen bond interactions. HPLC studies and adsorption isotherms performed in water have found that molecular imprinting affords a significant improvement in $\mathrm{K}_{\mathrm{a}}$ for phosphate and phosphonate affinity over a randomly functionalized xerogel. Affinities for these materials offer about an order of magnitude improvement in affinity compared to analogous small molecule receptors reported in the literature. The xerogel matrix appears to participate in host-guest interactions through anionic charge buildup with increasing $\mathrm{pH}$.
\end{abstract}




\section{Acknowledgment}

The authors would like to thank Dr. Robert Lagasse and Mr. John

Schroeder yor the BET surface area analyses and their helpful discussions. 


\section{Contents}

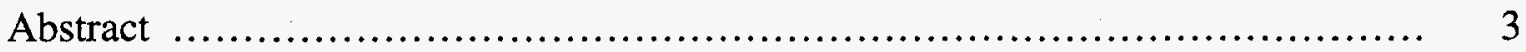

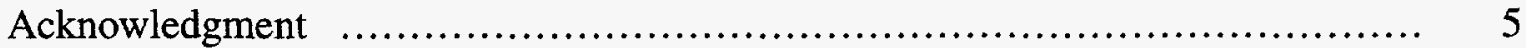

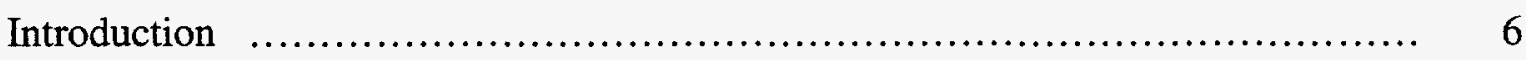

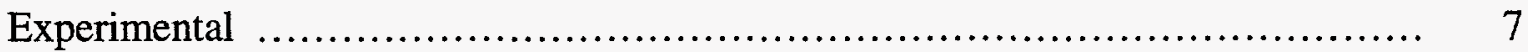

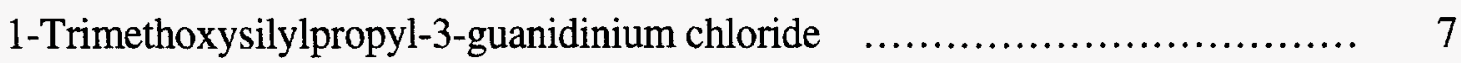

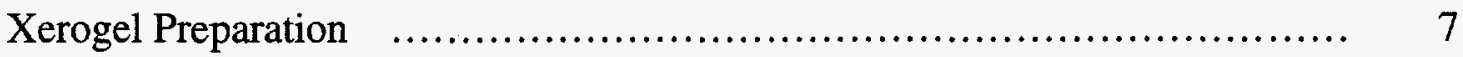

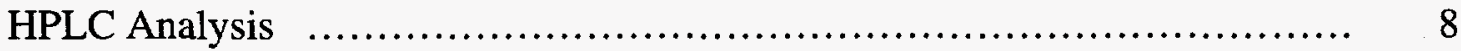

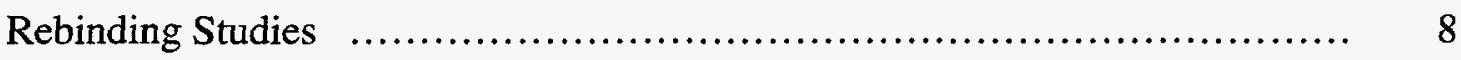

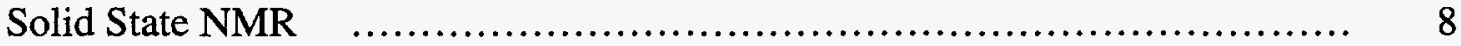

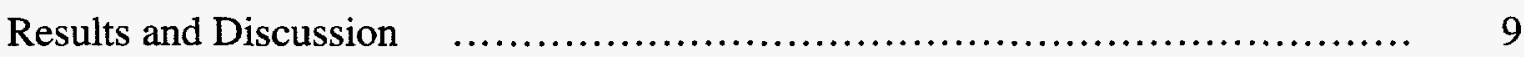

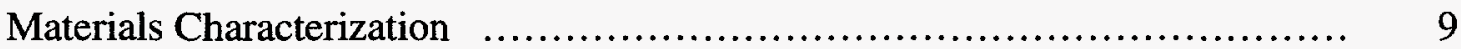

Host-Guest Interactions ................................................ 10

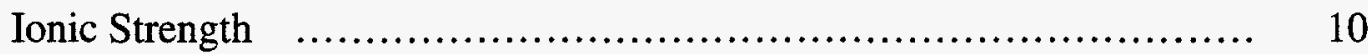

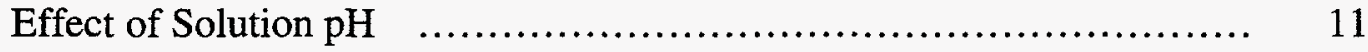

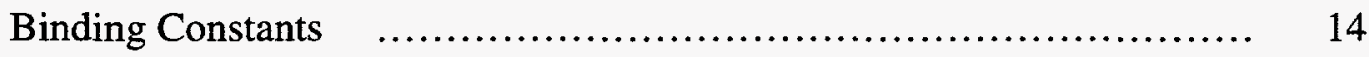

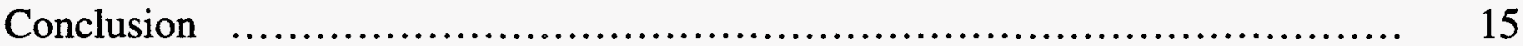

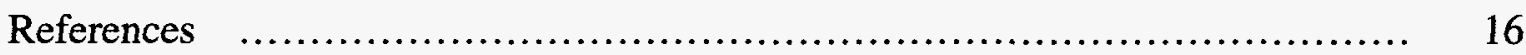

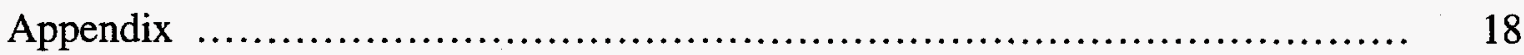

\section{Figures}

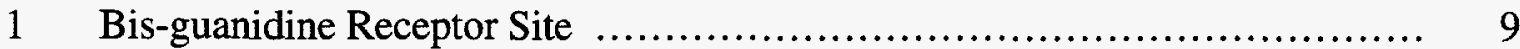

2 HPLC Study of Effect of Ionic Strength to Substrate Retention Time ........... 11

3 HPLC Study of Effect of Solution $\mathrm{pH}$ to Substrate Retention Time ............. 12

$4 \quad$ Bis-guanidine Receptor Site Interaction with PPA at Low and High $\mathrm{pH}$........ 13

5 HPLC Capacity Factors of Template and Non-Templated Xerogels $\quad \ldots \ldots \ldots \ldots . .13$

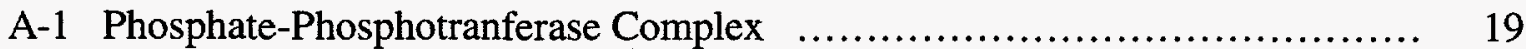

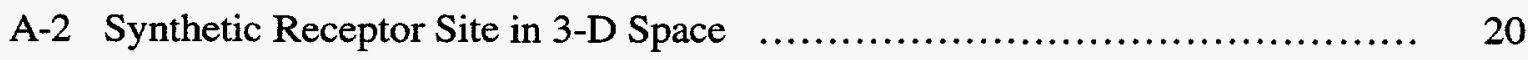

A-3 Model of Energy Minimized Guanidine Functionalized Silicate $\ldots \ldots \ldots \ldots \ldots \ldots . \quad 21$

\section{Tables}

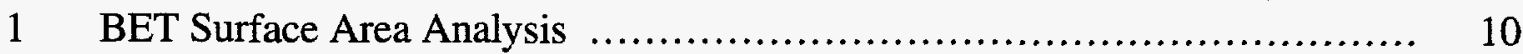

2 Binding Data of Imprinted and Non-Imprinted Xerogels ..................... 14 


\section{Synthetic Molecular Receptors for Phosphates and Phosphonates in Sol-Gel Materials}

\section{Introduction}

The selective and rapid detection of phosphate and phosphonate compounds, which include numerous biologically important signaling molecules (1-3) as well as pesticides and chemical warfare agents (4), is dependent upon the development of efficient host-guest systems. Various solution phase synthetic molecular host-guest systems have been developed to selectively bind phosphate esters using hydrogen bonding and electrostatics to achieve high affinity (5-9). A major drawback is the inability of these systems to achieve high complexation in the presence of water, a situation in which the detection of these compounds is desired. In contrast to these small molecule hosts, self-assembled Langmuir monolayers with guanidine functionality have produced some high binding constants for nucleotides in water through guanidine-phosphate pairing (10). It is believed that the monolayer host systems have some uniquely structured water near the interface that enhances host-guest binding, a feature non-existent for small molecule systems which operate in bulk water. Molecular receptors embedded in polymer scaffolds, like proteins, may offer interfacial reordering of water near the receptor that could enhance substrate binding $(11,12)$. Although it is unclear how to mimic proteins in this regard, efforts into the design and preparation of molecular receptors on polymer matrices may lead to the development of molecular recognition materials with enhanced selectivity and sensitivity under aqueous conditions.

Successful preparation of synthetic receptors in crosslinked polymers via the molecular imprinting methodology has generated a broad range of materials with molecular recognition properties (13). This method has already demonstrated that some highly selective receptor sites can be built for complex molecules, such as sugars (14), amino acids (15), peptides (16), nucleosides (17), and others, in polar organic solvents. Some strides in binding affinity for hostguest interactions in aqueous solution have been made in recent years $(18,19)$. However, selectivity and affinity in the presence of water remains a problem in these organic based materials.

We describe herein a new silica sol-gel molecular imprinted material for aqueous phase recognition of phosphate and phosphonate substrates. The receptors are functionalized with the guanidine moiety which provides specific points of interaction in the aqueous environment. The guanidine residue was chosen for its ubiquitous presence in protein receptors sites often acting as the main interaction point for phosphate compounds (20). The guanidinium-phosphate interaction employs a combination of electrostatic as well as bidentate hydrogen bonds to achieve high recognition properties (21). Glanidine alkyl silanes were used to functionalize the silica matrix formed by a sol-gel process. Frevious studies of imprinting in silica gels have demonstrated that metal oxides can provide for good affinity and selectivity of guest substrates in organic and aqueous solutions (22-26). The sol-gel process for molecular imprinting introduced here offers the 
ability of designing and building the material's matrix starting at the molecular level allowing facile tailoring of the material's polarity, pore dimension, and surface functionalization. Additionally, silica sol-gels offer many desirable features as the scaffold for molecular receptor sites which include a hydrophilic surface, optical transparency (for applications as sensor materials), and a highly crosslinked, robust structure with high surface area.

\section{Experimental}

General. Silane reagents were obtained from Gelest, Inc. Reagent 3-Amino-1trimethoxypropylsilane was distilled prior to use. Water was purified through a Barnstead Type D4700 NANOpure Analytical Deionization System. 1-H-pyrazole-1-carboxamidine hydrochloride reagent was prepared by the reported procedure (27). Solution phase ${ }^{1} \mathrm{H},{ }^{13} \mathrm{C}$, and ${ }^{31} \mathrm{P} N M R$ experiments were performed on a Bruker AM300 NMR spectrometer, and infrared spectra were obtained on a Perkin-Elmer 1750 FTIR spectrophotometer. Mass spectroscopy was performed by Mass Consortium, Corp.

1-Trimethoxysilylpropyl-3-guanidinium chloride (1). A solution of 3-amino-1trimethoxypropylsilane (10.0 g, $55.8 \mathrm{mmole})$ and 1-H-pyrazole-1-carboxamidine hydrochloride $(8.20 \mathrm{~g}, 55.9 \mathrm{mmole})$ in dry methanol $(30 \mathrm{~mL})$ was stirred for 15 hours at room temperature. The solvent was removed in vacuo leaving a viscous, colorless oil which was purified by Kugelrohr distillation $\left(150^{\circ} \mathrm{C}, 100 \mu \mathrm{mHg}\right)$ to remove the pyrazole byproduct. A clear, colorless, viscous oil of the product 1 remained $(12.7 \mathrm{~g}, 88 \%)$. ${ }^{1} \mathrm{H}$ NMR $\left(\mathrm{CDCl}_{3}\right) \delta 7.83\left(\mathrm{t}, \mathrm{J}=6.5 \mathrm{~Hz}, 1 \mathrm{H}, \mathrm{CH}_{2} \mathrm{~N} \underline{H}\right)$, 7.07 (br s, $\left.4 \mathrm{H}, \mathrm{N}_{2}\right), 3.58\left(\mathrm{~s}, 9 \mathrm{H}, \mathrm{OC}_{\mathrm{H}_{3}}\right), 3.20\left(\mathrm{dt}, \mathrm{J}=6.5,6.5 \mathrm{~Hz}, 2 \mathrm{H}, \mathrm{NHC} \underline{H}_{2}\right), 1.72(\mathrm{~m}$, $\left.2 \mathrm{H}, \mathrm{C}_{2}\right), 0.72\left(\mathrm{t}, \mathrm{J}=7.8 \mathrm{~Hz}, 2 \mathrm{H}, \mathrm{Si}-\mathrm{C}_{2}{ }_{2}\right) .{ }^{13} \mathrm{C} \mathrm{NMR}\left(\mathrm{CDCl}_{3}\right) \delta 157.75,50.59,43.31,22.42$, 5.83. IR (NaCl) $3330,3166,2946,2850,1652,1469,1192,1083,819 \mathrm{~cm}^{-1}$. High resolution MS calcd for $\mathrm{C}_{7} \mathrm{H}_{20} \mathrm{~N}_{3} \mathrm{O}_{3} \mathrm{Si}$ : 222.1274. Found: 222.1281 .

Xerogel Preparation. Ethanol $(305 \mathrm{~mL})$ and tetraethoxysilane $(305 \mathrm{~mL})$ were stirred in a $1 \mathrm{~L}$ vessel followed by the addition of water $(24.5 \mathrm{~mL})$ and $1 \mathrm{~N}$ aqueous $\mathrm{HCl}(1 \mathrm{~mL})$. The mixture was warmed to $60^{\circ} \mathrm{C}$ with stirring for 1.5 hours, then cooled to room temperature to afford the homogeneous sol solution. To the sol $(91 \mathrm{~mL})$ was added $0.1 \mathrm{M}$ aqueous $\mathrm{NH}_{4} \mathrm{OH}(9.1$ $\mathrm{mL}$ ). The solution gelled overnight and was aged in a closed container at $50^{\circ} \mathrm{C}$ for one day. The gel was then crushed, washed with ethanol twice, collected, placed in fresh ethanol $(200 \mathrm{~mL})$, and kept at $50^{\circ} \mathrm{C}$ overnight. For molecular imprinting the gel was collected and placed in a $100 \mathrm{~mL}$ solution of ethanol containing 1 ( $8.0 \mathrm{mmole})$ and phenylphosphonic acid $(4.0 \mathrm{mmole})$ template and the mixture incubated for another day at $50^{\circ} \mathrm{C}$. The solvent was subsequently evaporated at $50^{\circ} \mathrm{C}$ over a period of 12 hours. Blank and randomly functionalized xerogels were prepared identically with the exclusion of 1 and phenylphosphonic acid (PPA) for the blank gel and of PPA for the randomly functionalized gel. The xerogel was then crushed to a 75-250 micron particle size, 
washed with ethanol, and dried under vacuum at $60^{\circ} \mathrm{C}$ for a day. Prior to rebinding or HPLC studies, all materials were washed three times with $1 \mathrm{~N}$ aqueous $\mathrm{HCl}$ solution $(100 \mathrm{~mL} / \mathrm{g}$ xerogel) by swirling one hour for each wash at room temperature. The gels were then washed liberally with pure water followed by drying under vacuum at $60^{\circ} \mathrm{C}$ overnight. Quantitative removal of the PPA template was determined by UV analysis (PPA in $50 \%$ methanol/1 $\mathrm{N}$ aqueous $\mathrm{HCl}, \varepsilon=8332$ at $210 \mathrm{~nm})$.

HPLC Analysis. Xerogels processed to a particle size of 25-38 $\mu \mathrm{m}$ were slurry packed into a $4.6 \mathrm{~mm}$ i.d. $\mathrm{x} 100 \mathrm{~mm}$ HPLC column which was connected to a Waters 600-MS HPLC fitted with a Waters 484 tunable wavelength UV detector set at $260 \mathrm{~nm}$. All studies used a mobile phase consisting of $95 \%$ aqueous buffer solution $/ 5 \%$ acetonitrile. The ionic strength dependence study used an aqueous buffer composed of $0.01 \mathrm{M}$ potassium phosphate adjusted to $\mathrm{pH} 6.0$ with either $\mathrm{HCl}$ or $\mathrm{KOH}$, and the ionic strength was adjusted to the appropriate value by the addition of $\mathrm{KCl}$. The $\mathrm{pH}$ dependence study used an aqueous buffer composed of $0.01 \mathrm{M}$ potassium phosphate adjusted to the appropriate $\mathrm{pH}$ with either $\mathrm{HCl}$ or $\mathrm{KOH}$, where the ionic strength was maintained at $0.05 \mathrm{M}$ with the addition of $\mathrm{KCl}$. Capacity factors for Figure 5 were determined using acetone as the void volume marker, an aqueous phase of $0.01 \mathrm{M}$ potassium phosphate buffer adjusted to $\mathrm{pH} 6.0$ or 8.0 , and ionic strength of $0.05 \mathrm{M}$.

Rebinding Studies. Xerogel $(50 \mathrm{mg})$ at $75-150 \mu \mathrm{m}$ particle size was placed in a solution containing a phosphate or phosphonate substrate at various concentrations in a volume such that the total bound substrate in the xerogel amounted to less than 10 mole \% of the total substrate in solution. The $\mathrm{pH}$ of the solution was adjusted to $\sim 5$ using the substrates as the buffering medium. Although the solution equilibrates with the xerogel in minutes the solution was swirled overnight prior to analysis. An aliquot was taken from the solution and analyzed for depletion by an acid molybdate/Fiske \& SubbaRow reducer assay (Sigma Chemicals) for $\mathrm{PO}_{4}$ or by ${ }^{31} \mathrm{P}$ NMR for PPA. The binding data were evaluated by Scatchard analysis giving linear plots over the concentration range o: $1-10 \mathrm{mM}$. Binding constants $\left(\mathrm{K}_{\mathrm{a}}\right)$ and binding capacities (guanidine:substrate) are reported in Table II.

Solid State NMR. Direct polarization ${ }^{29} \mathrm{Si}$ solid state MAS NMR spectra were recorded on a Bruker AMX 400 spectrometer at a resonant frequency of $79.500 \mathrm{MHz}$ using a $7 \mathrm{~mm} \mathrm{bb}$ MAS probe and a $4 \mathrm{kHz}$ spinning speed. The reference was external $\mathrm{Q}_{8} \mathrm{M}_{8}(\delta=11.5 \mathrm{ppm})$. These spectra were recorded with a delay time of 300 seconds which is several times longer than the relaxation times of the sample to ensure quantitative spectra of the $\mathrm{Q}$ silicon species, where $\mathrm{Q}^{\mathrm{n}}$ $=\mathrm{Si}(\mathrm{OSi})_{\mathrm{n}}(\mathrm{OR})_{4 \mathrm{n}}$. Cross-polarization ${ }^{29} \mathrm{Si}$ spectra of the $4 \%$ xerogel were recorded at $39.7 \mathrm{MHz}$ on a Tecmag console interfaced to a Chemagnetics spectrometer. A $7 \mathrm{~mm}$ MAS probe, a $3.5 \mathrm{kHz}$ spinning speed, a contact time of $6 \mathrm{~ms}$ and a delay time of 4 seconds were used. The crosspolarization time was chosen so that the $T$ resonances and the $\mathrm{Q}^{2}$ and $\mathrm{Q}^{3}$ resonances were expected to be quantitative. The resonarces of the $\mathrm{Q}$ and $\mathrm{T}$ silicon species were deconvoluted using 
Gaussian components to calculate the extents of reaction and the relative amounts of $Q$ and $T$ silicons.

\section{Results and Discussion}

The molecular imprinting technique employed for the sol-gel materials allowed surface functionalization of the matrix to maximize accessibility of receptor sites while minimizing structure modification of the gel matrix. $\mathrm{A} \mathrm{SiO}_{2}$ xerogel was first prepared from tetraethoxysilane using a standard literature procedure for sol-gel processing (28). The xerogel was functionalized with the guanidine siloxane monomer, 3-trimethoxysilyl propyl-1-guanidinium chloride (1), prepared by reaction of 1-trimethoxysilylpropyl-3-amine with $1-\mathrm{H}$ pyrazole-1-carboxamidine hydrochloride. The siloxane monomer 1 was condensed onto the silica surface in ethanol solution in the presence of the template molecule, phenylphosphonic acid (PPA), in a 2:1 ratio to generate a receptor site as ideally illustrated in Figure 1. The finished material was dried, gently ground, and sieved to appropriate size.

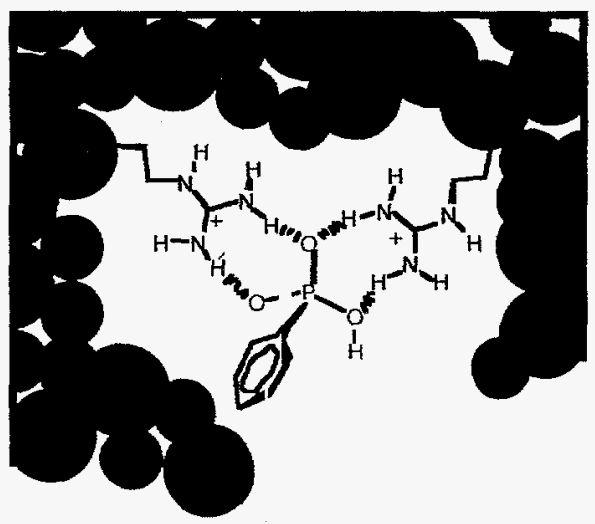

Figure 1. Idealized Bis-guanidine Receptor Site for Phosphonate.

\section{Materials Characterization}

Structural information for the xerogels was obtained through ${ }^{29} \mathrm{Si}$ solid state MAS NMR providing quantitative determination of the extent of condensation of the matrix and functionalization with 1 . Direct polarization ${ }^{29} \mathrm{Si} N M R$ was used to quantify the $\mathrm{Q}$, or $\mathrm{Si}(\mathrm{OR})_{4}$, species in the silica gel, where $\mathrm{R}=\mathrm{Si}, \mathrm{H}$, or ethyl (29). From the abundance of various $\mathrm{Q}$ species the extent of condensation of matrix silica could be determined. The blank xerogel was found to have $90 \pm 1 \%$ condensation indicating high crosslinking. A comparison of blank xerogel and xerogel functionalized with 1 showed that 1 to 4 mole $\%$ functionalization does not affect condensation of the gel matrix. Cross-polarization experiments measuring the $\mathrm{T}$ silicon ( $\mathrm{SiR}^{\prime}(\mathrm{OR})_{3}$, where $\mathrm{R}=\mathrm{Si}, \mathrm{H}$, or ethyl and R' = propyl-3-guanidinium) of covalently bound 1 determined an incorporation of 1 into the gel at $93 \pm 10 \%$ with an extent of condensation of $91 \pm$ $2 \%$. Thus, the procedure used for surface functionalization was successful with near quantitative coupling of siloxane monomer to the matrix and an approximate three point covalent attachment.

Surface area analyses were performed to determine any gross structural changes that might occur upon guanidine functionalization of the xerogel surface. Table I shows nitrogen BET analyses of blank xerogel and gels randomly functionalized with 1 at $2 \%$ and $4 \%$, and an imprinted gel with $4 \%$ of 1 and PPA imprinting at a 2:1 ratio of guanidine to PPA. The percentages of 1 are 
indicated as a mole percent relative to total silicon in the gel. With $2 \%$ functionalization the xerogel shows only a slight increase in surface area to $915 \mathrm{~m}^{2} / \mathrm{g}$ over the non-functionalized material (876 $\mathrm{m}^{2} / \mathrm{g}$ ) but a $65 \%$ increase in pore volume. Upon further functionalization to $4 \%$, the surface area drops appreciably $\left(836 \mathrm{~m}^{2} / \mathrm{g}\right)$ along with pore volume. Addition of the PPA template brings about a further decrease in surface area while pore volume remains constant. Overall the functionalization process does not significantly alter the xerogel structure, however, some trends were observed. Most noticeable is that surface functionalization with $\mathbf{1}$ leads to an increase in pore volume of $35-65 \%$. Since 1 can act as a capping agent for surface silanols, surface functionalization could minimize condensation across walls of collapsing pores leading to higher pore volumes for functionalized xerogels $(30)$. We can offer no good explanation as to why the surface area decreases as functionalization increases from 2 to $4 \%$ and further with PPA imprinting. With an average calculated area per bound guanidine of $225 \AA^{2}$, site isolation is highly probable assuming random distribution.

\section{Table I. BET Surface Area Analysis}

\begin{tabular}{cccc}
\hline$\% 1 / \mathrm{SiO}_{2}$ & Templete molecule & $\begin{array}{c}\text { Surface area } \\
\left(\mathrm{m}^{2} / \mathrm{g}\right)\end{array}$ & $\begin{array}{c}\text { Pore volume } \\
\left(\mathrm{cm}^{3} / \mathrm{g}\right)\end{array}$ \\
\hline 0 & none & 876 & 0.63 \\
2 & none & 915 & 1.01 \\
4 & none & 836 & 0.86 \\
4 & PPA & 771 & 0.85 \\
\hline
\end{tabular}

\section{Host-guest Interactions}

Ionic Strength. In ar. effort to understand host-guest interactions of phosphate and phosphonate substrates to these sol-gel materials, several HPLC studies were performed. Relative affinities of a phosphonate diester and a phosphonic acid to blank and randomly functionalized 4\% guanidine xerogels were measıred in an ionic strength study to qualitatively determine the contribution of ionic interaction between the host and guest. The eluent used was a solvent mixture of $95 \% 0.01 \mathrm{M}$ potassium phosphate buffered water at $\mathrm{pH} 6.0$ and $5 \%$ acetonitrile. The ionic strength was adjusted with KCl. Specific interaction of the guanidines with the phosphonic acid substrate should involve a combination of electrostatics and hydrogen bonding. On the other hand, binding of phosphonate diester would occur solely through hydrogen bonds. Figure 2 shows the effect of ionic strength on retention time to blank and functionalized gels with acetone, diisopropylphenylphosphonate (DIPP), and phenylphosphonic acid (PPA) substrates. Increasing ionic strength is indicated with increasing darkness of the bar. Acetone, which has no specific 
interaction to the materials, shows essentially no difference in affinity to both gels and no effect due to changes in ionic strength. DIPP exhibits a high non-specific affinity to the blank xerogel, but this affinity diminishes upon functionalization of the gel. Conversely, PPA shows no affinity for the blank gel, but high affinity for the $4 \%$ guanidine gel. Functionalization of the gel with 1
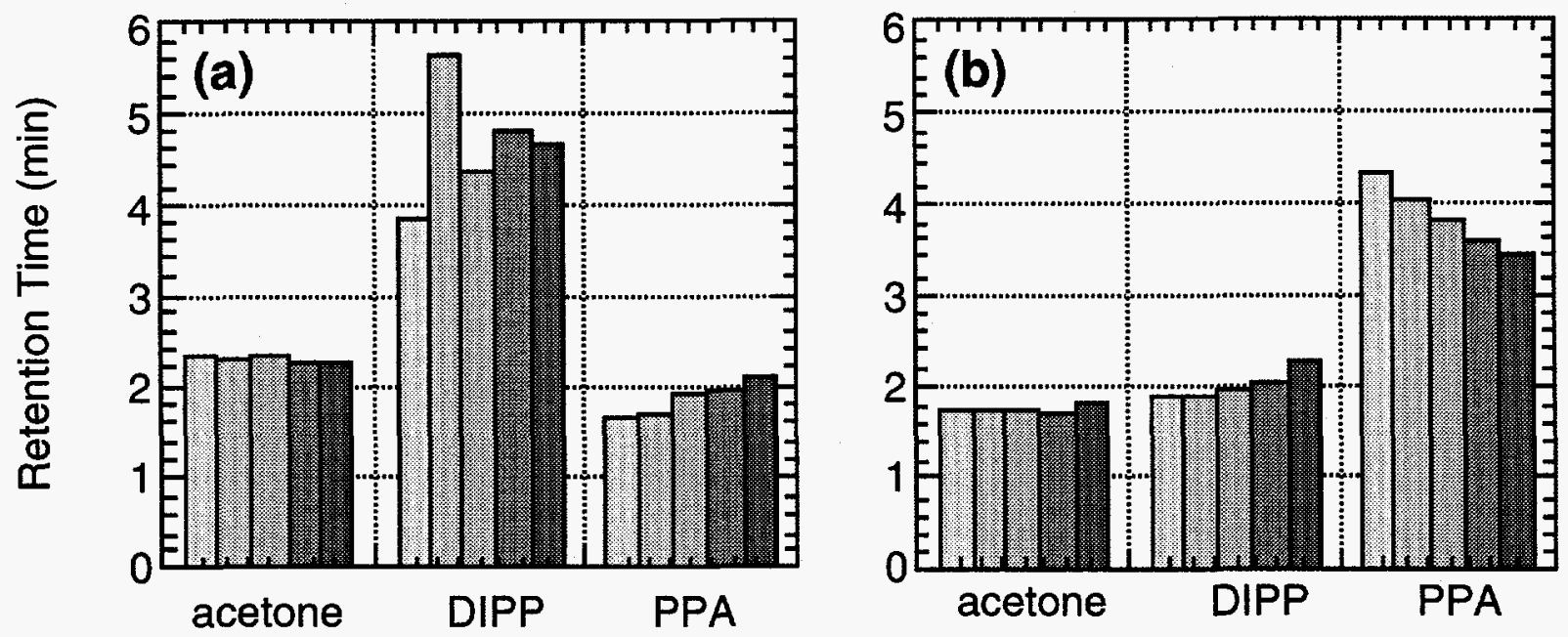

Figure 2. HPLC Study of the Effect of Ionic Strength on Substrate Affinity to Blank and Functionalized Xerogel. Graphs are of data from blank (a) and $4 \%$ guanidine (b) xerogels. The ionic strength increases from left to right above each substrate from $0.02,0.05,0.10,0.20$, to $0.50 \mathrm{M}$.

effectively minimizes non-specific interaction of phosphonate esters while adding specificity for phosphonic acids. The effect of ionic strength on the affinity of PPA to 4\% guanidine gel shows a trend of reduced affinity with increasing ionic strength. This is an expected observation for phosphonate-guanidine complexation where ionic pairing contributes to the binding interaction. Guanidine-phosphonate pairing has an additional hydrogen bond component which is believed to provide coordination of substrates in protein receptor sites (11). It is possible that hydrogen bonding also actively participates in these synthetic receptors and is responsible for the affinity observed at higher ionic strengths. From the data, however, it is evident that hydrogen bonding between DIPP and guanidine is negligible under the aqueous conditions.

Effect of Solution pH. HPLC studies on the effect of $\mathrm{pH}$ on substrate retention time shows a trend of diminishing affinity with increasing $\mathrm{pH}$. The mobile phase in these studies was a $5 \%$ acetonitrile/95\% aqueous phosphate buffer solution adjusted to the desired $\mathrm{pH}$, and ionic strength held at 0.05 with added $\mathrm{KCl}$. Figure 3 shows a comparison of blank and guanidine functionalized xerogel run with acetone, DIPP, and PPA at several $\mathrm{pH}$ values from 2 to 10 . The retention time of acetone is unaffected by changes in $\mathrm{pH}$ or gel type. For the phosphonate substrates, however, DIPP on the blank gel and PPA on functionalized gel show an inverse relationship between retention time (affinity) and $\mathrm{pH}$. Moreover, a complete loss of affinity is 

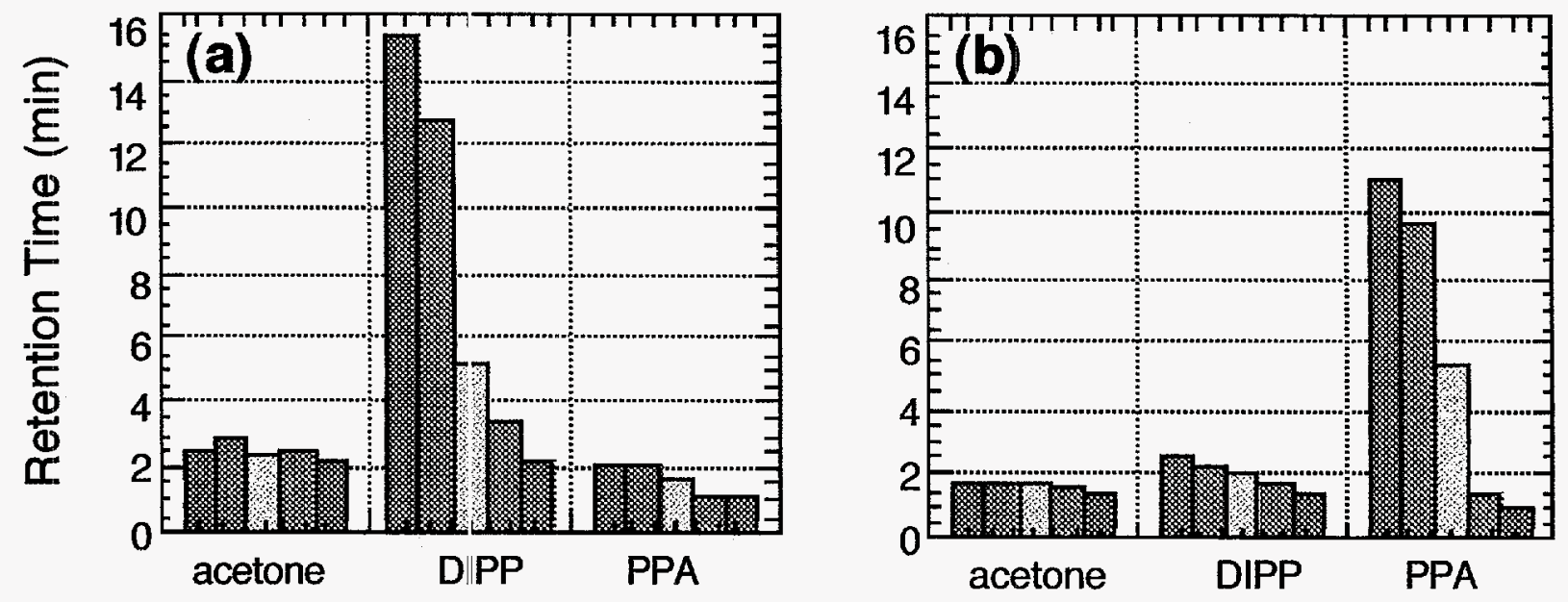

Figure 3. HPLC Study of the Effect of pH on Substrate Affinity on Blank and Functionalized Xerogels. Graphs are of data from blank (a) and $4 \%$ guauidine (b) xerogels. The $\mathrm{pH}$ increases from left to right in the order of 2.0, 4.0, 6.0, 8.0, and 10.0.

found at $\mathrm{pH} 8$ and above. In considering the specific interaction of the guanidine functionalized gel with PPA, strongest host-guest interactions should be found near neutral $\mathrm{pH}$. However, the data show that highest affinity is found at the lower $\mathrm{pH}$ values. The PPA affinity appears to be influenced by the extent of deprotonation of the acidic silanol groups on the silica matrix producing an increasingly anionic surface above $\mathrm{pH} 2$. Although the guanidine group can specifically bind with PPA the silica matrix dominates substrate interaction with changing solution $\mathrm{pH}$. Figure 4 illustrates the possible host-guest-matrix interaction at low and high $\mathrm{pH}$. At low $\mathrm{pH}$ the silica surface will be close to neutral charge allowing the guanidinium group to bind freely with PPA. At higher $\mathrm{pH}$ a negatively charged surface could force the cationic guanidinium to interact with the surface and restrict binding with the PPA guest (Figure 4). Other contributions for poor affinity at high $\mathrm{pH}$ could arise from ionic repulsion between the matrix and substrate or surface effects which may lower the $\mathrm{pK}_{\mathrm{a}}$ of guanidinium (13.6 in water) thereby minimizing electrostatic interactions with PPA at pH's lower than predicted. For the phosphonate diester DIPP it is unclear why there is a pH dependent non-specific interaction to the blank gel although reasonable explanations, which are out of the scope of this text, involving polar interactions with the surface could be made. Functionalization of the gel with $\mathbf{1}$, however, appears to remove the non-specific affinity at all $\mathrm{pH}$ levels.

An HPLC study comparing imprinted $v s$ randomly functionalized 4\% guanidine xerogels is shown in Figure 5. The two graphs present a comparison of capacity factors for DIPP and PPA to the xerogels at two different $\mathrm{pH}$ values of 6 and 8. At $\mathrm{pH} 6$, PPA shows a modest, yet 
significantly higher, affinity for the imprinted material with a $25 \%$ increase in the capacity factor over the randomly functionalized material. DIPP, on the other hand, shows a reduced affinity for the imprinted gel. The non-specific affinity for DIPP may be affected by differences in surface
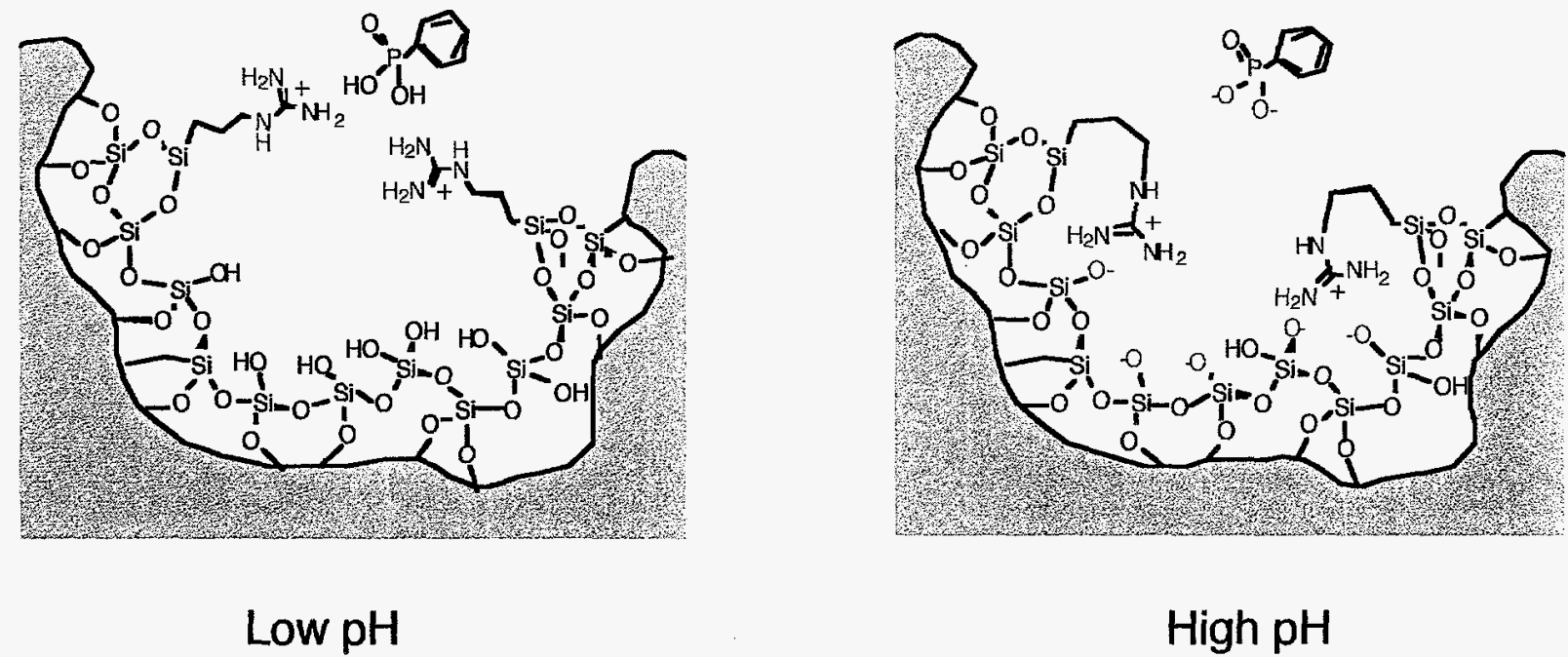

High pH

Figure 4. Possible Scenarios for PPA Interaction with the Guanidine-Functionalized Receptor Site at Low and High $\mathrm{pH}$.

pH 6

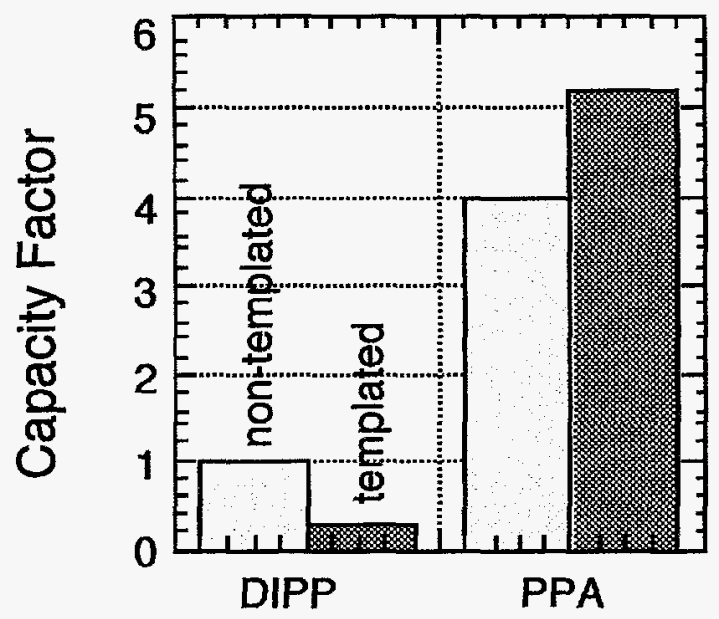

Ligand
pH 8

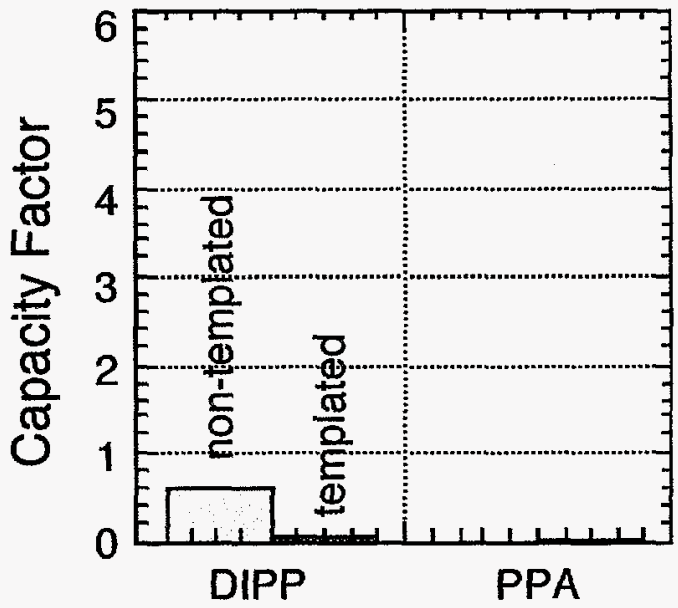

Ligand

Figure 5. A Comparison of HPLC Capacity Factors of Imprinted, or Templated, vs Non-templated Guanidinefunctionalized Xerogels at pH 6 and 8, Run with DIPP and PPA Substrates. 
area which appears as a byproduct of molecular imprinting as found through BET analysis (Table I). At pH 8, there is complete loss of affinity of PPA to the xerogel. It is evident from these studies that the surface near the receptor site can play a major role in the host-guest interactions. Investigation into ways to tailor these surfaces to improve affinities as well as tune the receptor to various conditions are forthcoming.

Binding Constants. Further evaluation of the molecularly imprinted xerogels was assessed through experimental binding isotherms obtained in water at $\mathrm{pH}$ 5. Table II shows binding constants $\left(\mathrm{K}_{\mathrm{a}}\right)$ and binding capacities (guanidine:substrate) for blank, $4 \%$ guanidine randomly functionalized, and $4 \%$ guanidine-PPA imprinted xerogels with phosphate $\left(\mathrm{PO}_{4}\right)$ and PPA as guest substrates. Blank xerogel was found to have negligible affinity for phosphate and PPA. On the other hand, randomly functionalized silica exhibited good binding constants for phosphate $\left(600 \mathrm{M}^{-1}\right)$ and PPA $\left(1100 \mathrm{M}^{-1}\right)$ in water. Furthermore, molecular imprinting with PPA yields an enhancement of $>2$ in binding constants for both phosphate $\left(\sim 1500 \mathrm{M}^{-1}\right)$ and PPA $(2600$ $\mathrm{M}^{-1}$ ) compared to randomly functionalized gel. These results show that it is possible to generate refined receptor sites in sol-gel materials through a surface imprinting technique. Additional effects, such as hydrophobicity, also appear to play a role in binding of substrates to the xerogels. For example, PPA, which has a hydrophobic phenyl substituent, exhibits about a two-fold higher $\mathrm{K}_{\mathrm{a}}$ value than the highly water soluble phosphate in both imprinted and non-imprinted functionalized materials. As has been observed with Langmuir monolayers, interfacial phenomena may promote stronger partitioning of the hydrophobic substrate to the gel bound receptor.

Table II. Binding Data of Imprinted and Non-imprinted Xerogels

\begin{tabular}{ccccc}
\hline$\%$ guanidine & $\begin{array}{c}\text { guanidine: } \\
\text { template }\end{array}$ & substrate & $\mathrm{K}_{\mathrm{a}}(\mathrm{M}-1)^{\mathrm{a}}$ & $\begin{array}{c}\text { guanidine: } \\
\text { substrate }\end{array}$ \\
\hline 0 & none & $\mathrm{PO}_{4}$ & 0 & \\
0 & none & $\mathrm{PPA}$ & 0 & \\
4 & none & $\mathrm{PO}_{4}$ & 600 & $1.6: 1$ \\
4 & none & $\mathrm{PPA}$ & $1100^{\mathrm{a}}$ & $2.0: 1$ \\
4 & $2: 1 \mathrm{PPA}$ & $\mathrm{PO}_{4}$ & 1400 & $2.5: 1$ \\
& & & $1600^{\mathrm{a}}$ & $2.8: 1$ \\
4 & $2: 1 \mathrm{PPA}$ & $\mathrm{PPA}$ & $2600^{\mathrm{a}}$ & $2.8: 1$ \\
\hline
\end{tabular}

a) Data obtained by ${ }^{31} \mathrm{P}$ NMR. 


\section{Conclusions}

We have shown through these initial studies that molecular imprinting in sol-gel materials can be successfully accomplished with a simple surface imprinting procedure. This method does not explicitly provide size and shape imprinting in the matrix, which is a feature of molecular imprinting. However, the method is chosen to be compatible to the sol-gel matrix, provide quantitative surface functionalization while maintaining high surface area and large pore size, and allow rapid equilibration of the receptor sites to solution. Affinities measured in aqueous solutions of phosphate and phosphonate substrates to these imprinted xerogels are one to two orders of magnitude higher than analogous small molecule receptors including pre-organized bis- and trisguanidine receptors $(8,9)$. The guanidine-phosphonate pairing on the gel surface shows evidence of contributions from both ionic and hydrogen bonding interactions in aqueous solution.

However, the silica matrix exhibits increasing influence over the efficiency of the receptor site with rising $\mathrm{pH}$ due to build up of surface charge. It is anticipated that by tailoring the matrix surface the specificity of the receptors will improve and result in highly efficient molecular recognition materials for aqueous systems. 


\section{References}

1) Potter, B. V. L.; Lampe, D. Angew. Chem. Int. Ed. Engl. 1995, 34, 1933.

2) Klarlund, J. K.; Guilherrne, A.; Holik, J. J.; Virbasius, J. V.; Chawla, A.; Czech, M. P. Science 1997, 275, 1927.

3) Kauffmann-Zeh, A.; Thomas, G. M. H.; Ball, A.; Prosser, S.; Cunningham, E.; Cockcroft, S.; Hsuan, J. J. Science 1995, 268, 1188.

4) Chemical Warfare Agents: Toxicology and Treatment Marrs, T. C.; Maynard, R. L.; Sidell, F. R., Eds.; John Wiley \& Sons: New York, 1996.

5) Hirst, S. C.; Tecilla, P.; Geib, S. J.; Fan, E.; Hamilton, A. D. Israel J. Chem. 1992, 32, 105.

6) Czarnik, A. W. SPIE - Fiber Optic Medical and Fluorescent Sensors and Applications 1992, $1648,164$.

7) Deslongchamps, G.; Galán, A.; Mendoza, J. d.; Rebek, J. J. Angew. Chem., Int. Ed. Engl. 1992, 31, 61 .

8) Dietrich, B.; Fyles, D. L.; Fyles, T. M.; Lehn, J.-M. Helv. Chim. Acta 1979, 62, 2763.

9) Dietrich, B.; Fyles, T. M.; Lehn, J.-M.; Pease, L. G.; Fyles, D. L. JCS Chem. Comm. $1978,934$.

10) Sasaki, D. Y.; Kurihara, K.; Kunitake, T. J. Am. Chem. Soc. 1991, 113, 9685.

11) Blokzijl, W.; Engberts, J. B. F. N. Angew. Chem. Int. Ed. Engl. 1993, 32, 1545.

12) Schwabe, J. W. R. Curr. Opin. Struct. Biol. 1997, 7, 126.

13) For a comprehensive review, see: Wulff, G. Angew. Chem. Int. Ed. Engl. 1995, 34, 1812.

14) Wulff, G.; Grobe-Einsler, R.; Vesper, W.; Sarhan, A. Makromol. Chem. 1977, 178, 2817.

15) Sellergren, B.; Lepistö, M.; Mosbach, K. J. Am. Chem. Soc. 1988, 110, 5853.

16) Ramström, O.; Nicholls, I. A.; Mosbach, K. Tetrahedron: Asymmetry 1994, 5, 649.

17) Shea, K. J.; Spivak; D. A.; Sellergren, B. J. Am. Chem. Soc. 1993, 115, 3368.

18) Andersson, L. I. Anal. Chem. 1996, 68, 111.

19) Andersson, L. I.; Müller, R.; Vlatakis, G.; Mosbach, K. Proc. Natl. Acad. Sci. U.S.A. 1995, 92, 4788.

20) Calnan, B. J.; Tidor, B.; Biancalana, S.; Hudson, D.; Frankel, A. D. Science 1991, 252, 1167.

21) Cotton, F. A.; Day, V. W.; Hazen Jr., E. E.; Larsen, S.; Wong, S. T. K. J. Am. Chem. Soc. 1974, 96, 4471.

22) Raman, N. K.; Anderson, M. T.; Brinker, C. J. Chem. Mater. 1996, 8, 1682.

23) Morihara, K.; Kurihara, S.; Suzuki, J. Bull. Chem. Soc. Jpn. 1988, 61, 3991.

24) Wulff, G.; Heide, B.; Helfmeier, G. J. Am. Chem. Soc. 1986, 108, 1089.

25) Heilmann, J.; Maier, W. F. Angew. Chem. Int. Ed. Engl. 1994, 33, 471.

26) Dickey, F. H. Proc. Natl. Acad. Sci. USA 1949, 35, 227.

27) Bernatowicz, M. S.; Xu, Y.; Matsueda, G. R. J. Org. Chem. 1992, 57, 2497. 
28) Brinker, C. J.; Keefer, K. D.; Schaefer, D. W.; Ashley, C. S. J. Non-Crystal. Solids 1982, $48,47$.

29) Sol-Gel Science: The Physics and Chemistry of Sol-Gel Processing Brinker, C. J.; Scherer, G. W., Eds.; Academic Press, Inc.: San Diego, 1990.

30) Prakash, S. S.; Brinker, C. J.; Hurd, A. J.; Rao, S. M. Nature 1995, 374, 439. 


\section{Appendix}

\section{Molecular: Modeling of Phosphonate Receptor Site}

Computer modeling was used to garner insights into phosphonate and phosphate molecular recognition in biological systems revealing key functional group interaction points used in nature. The functionality were isolated and transposed into a model synthetic receptor in a silica matrix and the lowest energy structure in the presence of a phosphonate substrate identified. These studies confirmed the viability of our approach towards a synthetic receptor as we found the matrix coalesced around the phosphare substrate with high host-guest binding energy.

Molecular modeling studies were performed to aid in the design of biomimetic molecular recognition materials that bind phosphate and phosphonate ligands. There are two design goals: 1) to examine phosphonate and phosphate binding in known biological systems and identify the key molecular recognition features, and 2) to build 3-D molecular models of a proposed receptor site in a synthetic material to evaluate possible interactions based on these key features. Phosphonate binding in natural and engineered materials was studied in three steps. First, we culled the protein data bank for suitable phosphate binding structures. Next, we evaluated the binding energy of these using a combined molecular mechanics/Monte Carlo technique. Finally, we suggested the positions of the engineered binding pocket atoms based on the previous results and ran Molecular Dynamics simulations of phosphate ion and a phosphonate molecule in a model aerogel.

Brookhaven's Protein 'Data Bank was searched for 'phosphate' (256 responses) and 'phosphonate' (30 entries) binding proteins. These structures were downloaded and investigated using MSI's Insight molecular modeling program. The binding pocket was determined to be a $20 \AA$ radius sphere surrounding the phosphate ligand (i.e., phosphate ion, NAD+, ATP, ADP, AMP). For all simulations we used the USF's Amber forcefield. The interactions included partial coulombic charges and van der Waals interactions (100 $\AA$ cutoff) which combine to approximate hydrogen bonds. A list of structures used in the final analysis were tabulated along with pertinent surface chemical properties. Eighteen of these which had the strongest intermolecular energy for the different binding agents were used in further binding analysis. MSI's docking module was then used to compute the binding energy of the phosphate ligand. This computer experiment randomly chooses positions of the bound molecule and evaluates the energy. Finally, the binding pockets were analyzed for the prevailing amino acid residues that lined the adsorption site. Some of the striking features found in the initial characterization of these proteins were the large number of hydrogen bonds (as many as three per phosphate oxygen) and their unusual tightness. Key functionality at the receptor site: include guanidinium from arginine, amine from lysine, imidazole from histidine, amide hydrogens from the protein backbone, and hydroxyls from serine and water. A representative example is shown in Figure A-1 of the phosphate-phosphotransferase complex. 
Electrostatics of the protein environment showed larger positive potential near the negatively charged phosphate oxygen compared to where the neutral (protonated) phosphate oxygens bind. Past mutant protein studies have shown that modifying this potential can alter which phosphate species (monobasic vs. dibasic) preferentially binds to a protein.

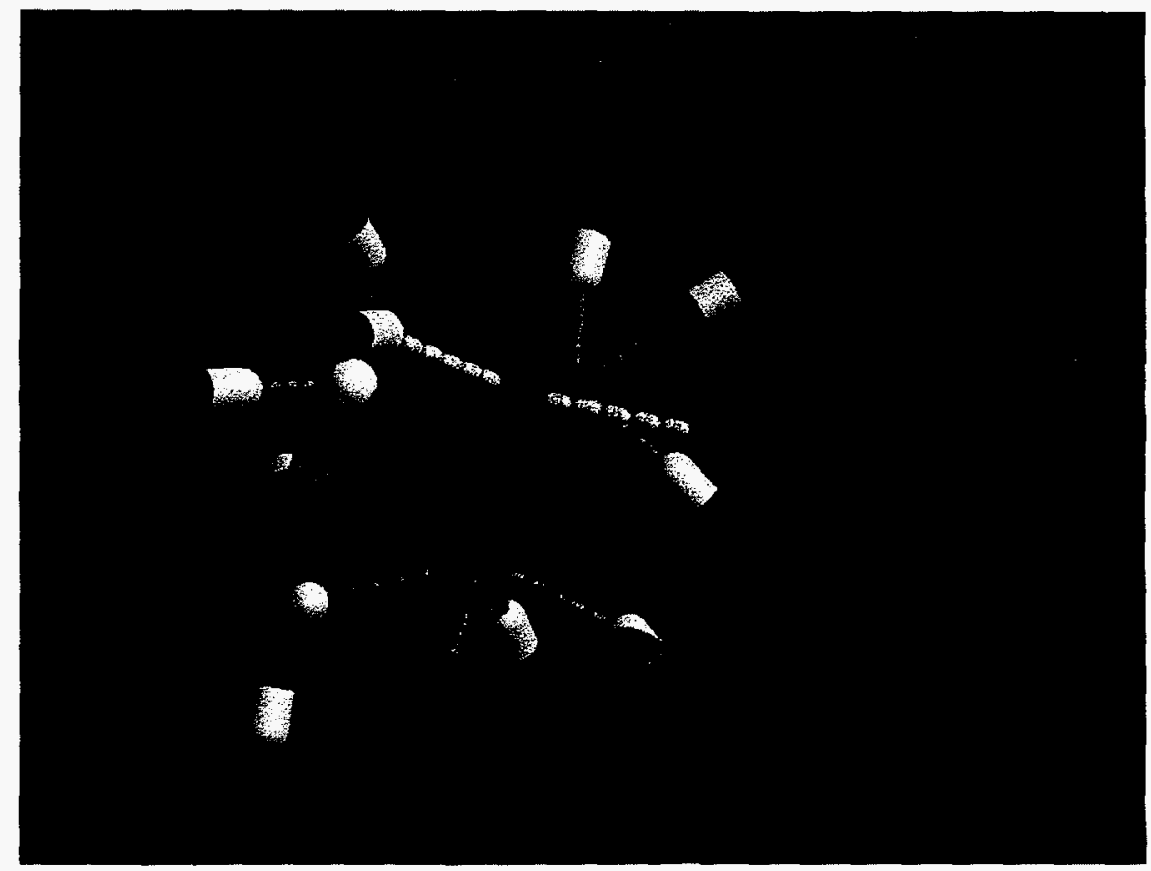

Figure A-1. Phosphate-phosphotransferase complex binding site.

In an effort to examine the proposed synthetic receptor we modeled it in 3-D space as an isolated site and as incorporated into a silicate matrix. In the isolated site our goal was to evaluate combinations of functional groups which maximize the number of possible interactions while minimizing steric and electrostatic repulsions. The evaluation consists of examining the possible spatial orientations that exist for a given set of groups. We used distances and angles from known protein-substrate complexes to help in the functional groups placement. We assumed the amines would maximally bind with the phosphate, and threw out sterically overlapping arrangements. A minimized structure was obtained showing high convergence of two guanidines and the anthracene diamine to the phosphate substrate. The energy minimized structure is shown in Figure A-2.

Modeling of the synthetic receptor in the silicate matrix was performed using Molecular Dynamics on a time domain of 100 picoseconds using a time step of one femtosecond. The functional group used was the guanidinium which was placed randomly in a porous silica model grown by cluster-cluster aggregation, based on experimental ${ }^{29} \mathrm{Si}$ NMR and small angle $\mathrm{X}$-ray 


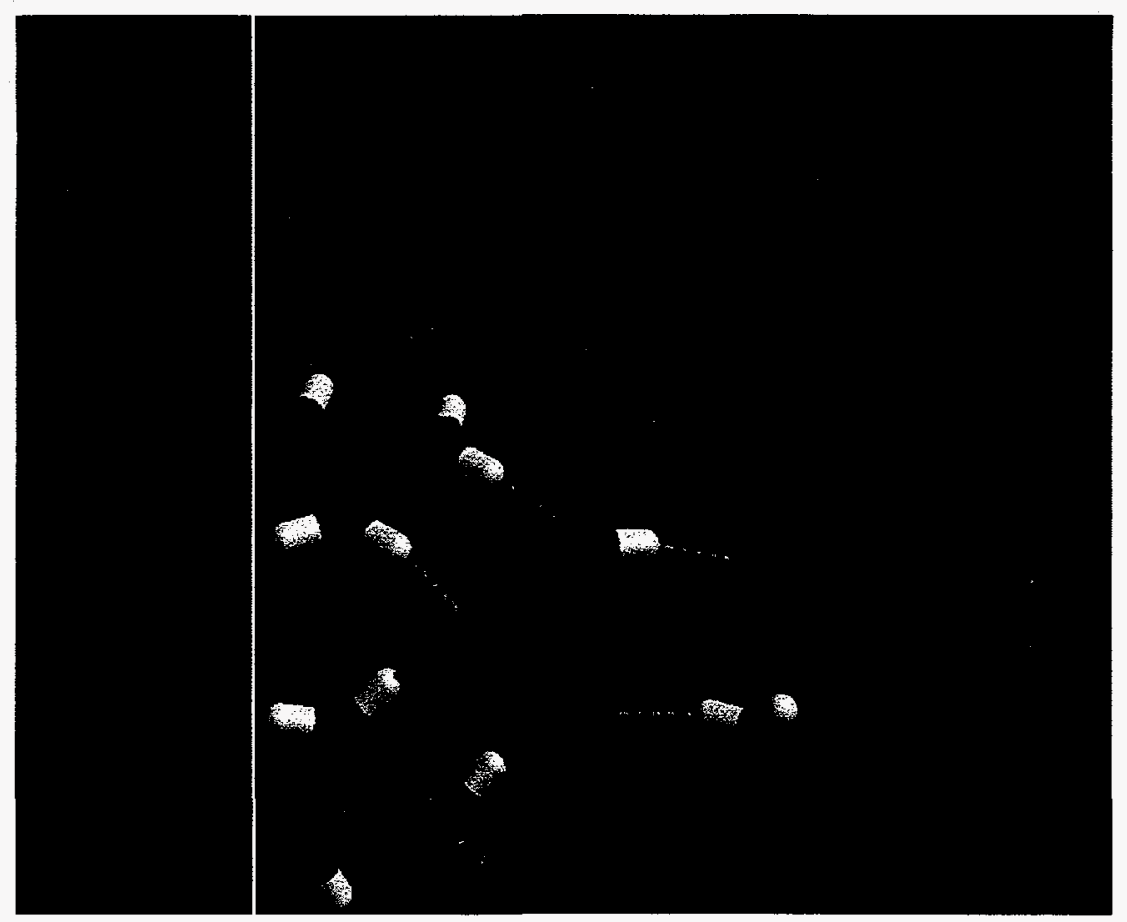

Figuri A-2. Proposed synthetic receptor site in 3-D space.

scattering results. A phosphate or phosphonate substrate was placed near the matrix surface and the system allowed to energy rninimize (Figure A-3). The extraordinary result is that the guanidine functionality collapsed around the phosphate, or phosphonate, ion as indicated by the pair correlation functions between nitrogen atoms and phosphate atoms. This suggests that a siloxane matrix functionalized with guanidinium groups would have good probability in forming receptor sites with high molecular recognition for phosphate or phosphonate ion. 


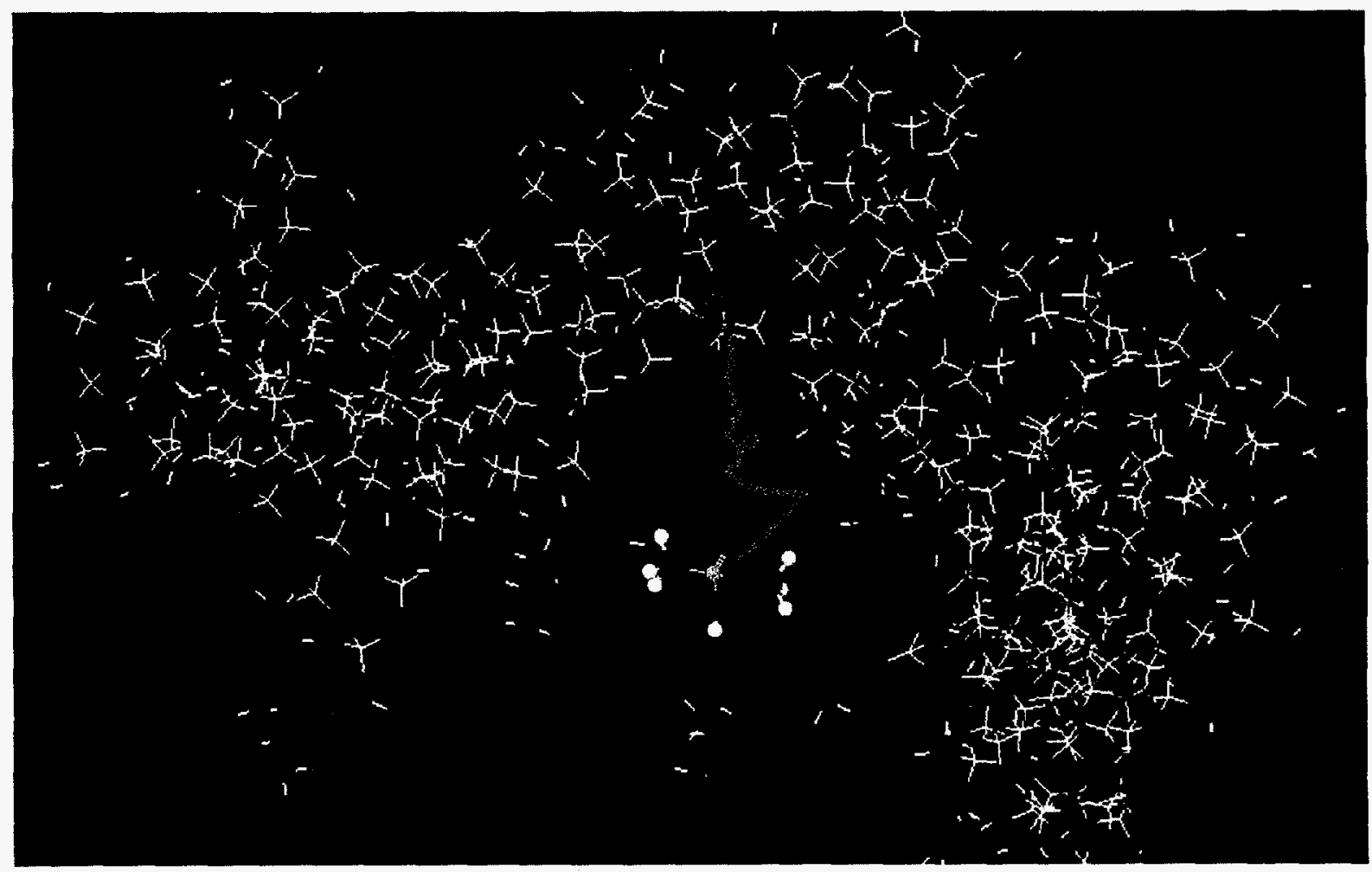

Figure A-3. Model of a silicate matrix randomly functionalized with guanidines in a molecular dynamics simulation with a phosphonate substrate. The blue line shows the trajectory of the substrate ending near a multi-guanidinium receptor site. 


\section{DISTRIBUTION:}

3 Prof. Kenneth J. Shea

University of California Irvine

Chemistry Department

Irvine, CA 92717

1 Dr. Daniel Rush

University of California, Irvine

Chemistry Department

Irvine, CA 92717

\begin{tabular}{|c|c|c|}
\hline MS & 1407 & D. Sasaki \\
\hline 1 & 1349 & C. J. Brinker \\
\hline 1 & 1349 & C. Ashley \\
\hline 1 & 1407 & T. Alam \\
\hline 1 & 1407 & R. Assink \\
\hline 1 & 1425 & A. Rirco \\
\hline 1 & 1425 & M. Butler \\
\hline 1 & 9214 & J. Sch oeniger \\
\hline 1 & 9214 & D. Roe \\
\hline 1 & 0727 & P. Pohl \\
\hline 1 & 1407 & R. Clough \\
\hline 1 & 0188 & C. E. .Meyers, LDRD Office \\
\hline 1 & 9018 & Central Technical Files, $8940-2$ \\
\hline 5 & 0899 & Technical Library, 4414 \\
\hline 2 & 0619 & $\begin{array}{l}\text { Review \& Approval Desk, } 12690 \\
\text { For DOE/OSTI }\end{array}$ \\
\hline
\end{tabular}

